\title{
The New Media and Digital Divide: Knowledge Gap Exacerbated
}

\author{
Sunny .E. Udeze, Ph.D. \\ Associate Dean, Faculty of Management Sciences, Enugu State University of Science and \\ Technology (ESUT) Enugu, Nigeria. \\ udezeemma@yahoo.com \\ $+\mathbf{2 3 4 8 0 3 3 4 0 2 8 8 5}$ \\ Oko, Theophilus \\ Department of Mass Communication, Enugu State University of \\ Science and Technology, Enugu.
}

\begin{abstract}
The Information Age driven by the internet has widened the gulf in knowledge obtained by different groups of people from the media. This paper observes that the degree of disparity in knowledge prior to the internet age is infinitesimal when juxtaposed with the present situation. It identifies discrepancies in access, use and ownership of the new media as causative factors. The paper recommends domestication of production of new media with regard to their hardware and software, incorporation of new media as a course of study in schools' curricula and establishment of government-sponsored internet centres as remedial measures.
\end{abstract}

Key words: New media, knowledge gap, digital divide.

\section{Introduction}

New information and communication technologies occasioned by advancement in technology in the present age have brought about such buzz words as information age, new media, digital divide, to mention but a few. The new communication devices and their applications have not only caused a deconstruction of definition of mass communication but have essentially changed the whole media landscape and journalism as a profession.

The society has witnessed such a phenomenal proliferation of computers and other communication devices that people are beginning to be euphoric about their positive impacts on their social, economic, cultural, political and academic lives. Such expectations and excitements are justified considering that apart from facilitating communication, the new information and communication technologies also prove useful in social networks, banking, commerce, health, environment, education and even in securing jobs among other things. Indeed the spectrum of human lives has been affected by the new media either positively or negatively.

In spite of the seeming diffusion of new information devices, there seems to be a startling disparity in their ownership, access and use among people across different parts of the globe. The implication is that the information gap or knowledge gap between the "information rich" and "the information poor" is getting wider by the day. The extent to which the knowledge gap has been widened further by the new media is what this discourse attempts to explore. 


\section{The New Media: An Exploratory Voyage}

Certain concepts do not submit to easy definition or explanation. The simple reason is that newness of anything, be it idea or item in the physical form is time-bound. The concept "new media" is not an exception. It has been in use since 1960s and has kept changing and expanding according to the dictates of technology (McQuail 2010, p.39). There was a time when book, magazine, newspaper, film, radio and television were classified as being new to the extent that they represented a marked improvement over their predecessor media. The inventions of the above-named media which have today been labeled old, traditional or dominant media were greeted with equal euphoria, interest, expectation and prediction as the contemporary new media (Rossier, 2001).

Scholars have however, attempted to define what new media is all about. Odofin (2011, p.80) sees the new media as encompassing all modern media and communication devices that have startlingly redefined, reshaped and restated geographical distances in innovative ways. According to the author, they include cyber culture ranging from blogging to social networks to online multiplayer gaming. On his part, Salau (2012, p.25) citing Otufodunrin states that new media are "interactive forms of communication that use the internet". Included as examples are podcasts, RSS leads, social networks, text messaging, blogs, Wikis, virtual words etc. McQuail (2010, p.136) opines that the new media are internet-based activities especially the public use of the internet which includes online news, advertising, broadcasting, the World Wide Web, forums etc.

One common thread that runs through all the definitions of new media is that new media in the present age of Information Revolution are the modern, technologically sophisticated devices which are dependent on the internet to function as platforms for media contents of various forms.

\section{The New and the Old Media: A Juxtaposition}

The new media are diametrically different from the old media in many respects. Disparities between the two classes of media can be viewed from the perspectives of their operations, uses, ownership, regulations and audiences.

The primary concern of operators of dominant media is mere production and distribution of media contents. New media are imbued with all those functions in addition to processing, exchanging and storing of information or media contents. For instance, television programmes are packaged and transmitted to television audiences. A scene captured with a smart phone can be posted to the internet, shared among friends on a social network, stored up in the mobile device and can be retrieved for future use.

One of the most palpable differences between the old and the new media is in new media's interactive or participatory nature. Livingstone (1999, p.65) postulates that "what is new about the internet may be the combination of interactivity with those features which were innovative for mass communication". Enabled by the internet, users of new media not only consume media contents but also have ample opportunity to make inputs to the contents or programmes 
irrespective of media forms - print or electronic. Owing to digitization, internet and their concomitant media convergence, interactivity has seized to be restricted to electronic media. This feat is not conceivable with the old media.

Ownership of old media is predominantly government. It was much later that private, religious, institutional, and political ownerships were witnessed. Nigeria Television Authority (NTA) and African Independent Television are government and privately owned media respectively. Who then owns the social media or the new media? While lack of identifiable ownership of new media holds a veneer of advantage in terms of freedom of expression, it has its shortcomings as it promotes the use of media for unhealthy and offensive ends (Ihebuzor 2012, p.16). Most materials uploaded in the social media are poorly edited and shows little or no effort at upholding ethics and law of the profession. This is because according to Collins (2008) the government and law do not control or regulate the internet in a hierarchical way as they do the old media." The National Broadcasting Commission (NBC) disciplines radio or television outfits whose contents or mode of operation run foul of broadcast codes. In the same vein any infraction by a newspaper organization attracts sanctions from Nigerian Press Council (NPC). Those regulatory bodies ensure strict adherence to professional standards while the new media are completely free from any institutional restraints. For the new media, operation is everybody to himself and God for us all. The concept of swinging your hand and minding the nose of the person behind you is not for them.

Old media audiences are termed Mass audience (Blumer in Ndolo 2006, p.25) hence the media are referred to as mass media. The opposite holds true for new media which have "demassified" or segmented audiences. New media audiences are in control with respect to which, how, when to consume media contents.

McQuail (2010, p.39) enunciated the specific features of the new media that distinguish them from old ones as interconnectedness, accessibility to users both as senders and receivers, interactivity, multiplicity of use, open-ended in character, ubiquity and "delocatedness".

\section{Knowledge Gap in the Pre-Digital Age: An Insight}

As the human fingers are naturally asymmetrical, so are there disparities in socio-economic status of individuals and nations of the world. Knowledge gap or information gap presupposes that there is a differentiation in information access and acquisition among different categories of people in a society as well as among different strata of nations in the universe. Baran and Davis (2009, p.276) state that knowledge gap is "systematic differences in knowledge between betterinformed and less-informed segments of a population". Severin and Tankard (1992, p.230) note that "there are haves and have-nots with regard to information just as there are haves and havenots with regards to material wealth". Tichenor, Donohue and Olien (1970, pp.159 - 160) while concurring that infusion of mass media information into a social system favours higher socioeconomic group than the lower group resulting in knowledge gap, also disagreed with the extremists' postulation that the lower status segment of the population have zero information. They contended that information richness or poverty is relative. 
Certain variables are responsible for the gap in knowledge among individuals some of which are level of income, education, experience and the individual. It is perhaps one or a combination of the factors that define an individual acquisition of media, access to media and use of media at any point in time. Owens - Ibie (2003, p.5) quoted Media Reach Nigeria (2009) as stating that media penetration among Nigerian adults is $79.9 \%$ for television, $82.6 \%$ for radio, $27.4 \%$ for newspaper, $21.0 \%$ for magazine, $66.9 \%$ for out-of-Home and $22.1 \%$ for internet.

Among the various media, there are still inequalities in their capacities to circulate information to the audiences. Taking into cognizance, the special knowledge required to access the content of the print media, the print media contribute in knowledge gap widening than the radio and television (Robinson, 1972). Conversely, Grabe, Karnhaus and Yelyan (2009) found out that it is easier for the less educated people to process and learn from television than newspaper information. McQuail (2010, p.489) corroborates that the capacity of television to benefit the less privileged members of the society stems from its ability to reach a higher proportion of a given population with much the same news and information and perceived credibility.

It may be pertinent at this juncture to ask: Did the television succeed in achieving the desired knowledge leveling target? Answer to the poser is not far to seek. Robinson and Levy (1986) discovered that "news learning from television does not give much confidence in the capacity of television to close knowledge gaps, even in the days of mass viewing".

Failure to close knowledge gap as the public anticipated is not limited to the television but extends to other media genres or types. Studies have shown that the efficacy of the mass media in knowledge gap narrowing remains a mirage as the gaps become wider and wider (Gaziano, 1997; Visvanath and Finnegan, 1996). This is not surprising because all types of media need different things that are not available to everybody. First is the problem of access. As we know, no matter how cheap radio, television, newspaper, magazine or computer may be, there are millions in different part of the world who cannot afford them. This group will never have the same knowledge level with those who can buy. Secondly, some of the media such as television and newspaper need electricity and literacy respectively. So many in the world are completely cut off by these problems, thereby increasing the knowledge gap. They are like people who live inside the ocean but are very thirsty. All the information from all these media just pass by them. The media are not for them, they neither contribute to nor consume the media contents. The bulk of them are found among the poor in rural area and urban slums of Africa, Asia and Latin America.

The situation that applies to individuals with respect to knowledge gap can be extrapolated to nations as they are not immune to socio-economic stratification. Knowledge inequality exists between the developed and wealthy nations of the world (the North) and the developing and poor nations, (the South). As Udeze (2005, p.22) posits the North has the wealth, skill and technology to acquire communication devices and access information than the South which is dependent on the North for communication equipment and human skills on account of poverty.

Barker and Dunn (1972, p.1396) succinctly state that until access to information services is universally available, those already rich in information will continue to be at advantage over the 
information poor. The observation by the duo provokes a poser: Can access to information services ever be "universally available?" No, is the answer.

\section{Digital Divide as an Exacerbation of Knowledge Gap}

The debate on the extent to which mass-mediated information has continued to widen instead of narrowing the knowledge gap was given fresh life and urgency by the invention of the internet with its great informative potential but variable diffusion and actual use (McQuail 2010, 489). The new communication technologies gave birth to a new expression termed "digital divide" (Norris, 2002) which is an advanced form, if not a successor to knowledge gap.

Organization for Economic Cooperation and Development (OECD, 2001, p.5) defines digital divide as:

The gap between individuals, households, business and geographic areas at different socio-economic levels with regard both to their opportunities to access information and communication technologies (ICTs) and their use of the internet for a wide variety of activities.

McQuail (2005, p.554) explains that digital divide means "the various inequalities opened up by the development of computer based digital means of communication." The scholar expatiates that high cost of equipment, dependence on advanced infrastructure and higher skills needed to communicate are factors that breed digital divide.

Bonfadelli (2002) found out that digital divide exists between the affluent, better-educated young adults and their less-affluent, less educated peers since the rich and educated obtain the internet and use it regularly for information while the poor and less-educated either do not have access to the internet or they use it only for entertainment. Watson (2003, pp.252 - 253) states that cyberspace is largely off-limits to the poor, the ill-educated and the unemployed at individual, community or national levels. He supported his assertion statistically by citing a 1997 study which revealed that $83 \%$ of Net users worldwide were in the US, compared with $6 \%$ in Europe, and $11 \%$ for the rest of the world. Of Africa's 700 million people, $0.1 \%$ had access to the Net. Little wonder then that Keniston and Kumar (in Press p.2) enthused that "Despite all utopia dreams, the information Age has so far touched only a tiny minority of world's population".

Whereas Katz and Rice (2002) consider differential diffusion in computer and other new technological devices as being at the root of digital divide, studies overwhelmingly point at different levels of skills at using information sources as the major cause of digital divide (Selwyn, 2004; Hargittai and Hinnant, 2008; Smith and Curtain 1997). Although his was not a study, Obijiofor (2012, p.51) was emphatic that the use of new media in Africa is limited to the middle and upper classes who are technologically savvy.

It is instructive to note that Obijiofor underscores the imperative of being technologically savvy because the other scholars have emphasized education as though it is a licence to using the new media. Apart from education, special skill is required to use the new media. Raji - Oyelade (2013, p.44) lists four categories of digital literate and illiterate people exist. The first, according 
to him is the e - literate literate who is educated and also knowledgeable in using digital technologies. The second class is the e - illiterate literate who has conventional education but lacks digital path in the labyrinth of digital space. The third is the illiterate e - literate who has poor education but is self trained in the half measure use of the basics of internet and electronic knowledge. The last group is the pretended e - literate who is a digital charlatan that relies on the assistance of the $\mathrm{e}$ - literate person to cover his illiteracy.

Advancing reasons why the digital divide has worsened the knowledge gap situation, Benneth and Iyengor (2008) trace it to the new media which caused a decline in consumption of mass media content which results in lower chance of exposure to public information and therefore wider knowledge gap. For Keniston and Kumar (2003, pp.6 - 9), the four notable knowledge dividers are income, linguistic and cultural differences, growing digital gap between the rich and the poor nations and emergence of elite group. Ones income level empowers one to acquire computer which is costly as well as pay for internet services.

Again there is dominance of English language on the Web. For instance Web sites in the world are in English" (Keniston and Kumar p.6). If that is the position, what happens to the nonEnglish speaking people willing to use the net? The authors further explain that a very large gap separates Asian Americans and Whites from their blacks and Hispanic counterparts with regard to internet access.

The digital gap between the industrialized nations and their developing (or is it underdeveloped?) counterparts will certainly get wider because in terms of skill, technology and wealth, the North is head and shoulder above the South. As far as new information and communication technologies are invented and the trend will continue, (Mediamorphosis, Fidler 1997, p.289) knowledge gap cannot be closed but will be exacerbated.

\section{Bridging the Digital Gap: Rumination}

There is an axiomatic statement that problem identified is problem half-solved. The authors are of the candid opinion that it is a high time the issue of digital divide is tackled headlong by literally lighting a candle to dispel darkness instead of cursing it. It may sound preposterous to envisage an immediate and quick closure of digital gap which has gotten so wide that narrowing (not closing) it seems an uphill task or a mere hallucination. What is advocated is pragmatic, concerted and sustained effort by the disadvantaged individuals and nations to bridge the gap through the following suggestions proffered.

There should be a domestication of production of communication technologies by the poor and developing nations of the world. Outright dependence on foreign technologies is counterproductive. Developing and under-developed countries are not bereft of inspiration, skill or manpower to imitate the North. Communication is so commercialized and lucrative in the contemporary time that nations that neglect it do so at their own peril. Investments in communication are well-made as it will cheapen the cost of devices and ipsofacto increase the number of people that can acquire them. 
Localization of contents of the new media should naturally follow domestication of production. He who pays the piper dictates the tune is an age long aphorism. It stands to reason therefore that the country that produes the computer hardware has the prerogative to dictate the software. This is the only way to challenge the dominance of English language on the internet.

Internet or new media should of necessity be incorporated into the curricula of schools from primary to tertiary levels. This should be a serious departure from what obtains in most universities in Nigeria where computer education is taught as a course without any functional computer to complement the theoretical lessons with practical. It rankles. Every graduate of primary, secondary and tertiary institutions should be digitally literate.

Government at all levels should also consider as a matter of urgency, building and equipping internet centres where people will not only access internet free of charge but also be trained on the practical aspects of internet use. Most importantly, governments should endeavour to improve the economic lives of citizens so as to empower them to acquire new information and communication technologies.

\section{Conclusion}

The new media come with glaring benefits in today's information age albeit with a negative consequence of polarizing inhabitants of the universe into two unequal groups namely, the digital privileged and the digital underprivileged classes.

In the era of mass media and society, scholars were seriously concerned about the gap in the knowledge between the information rich and the information poor. What they did not realize at the time was that knowledge gap is a precursor to digital divide which is a deeper and wider gulf between individuals and nations who can acquire and use the internet or new media and those who cannot.

Though the gap seems difficult if not impossible to close or level, it can albeit be bridged if those at the disadvantaged end of the divide take pragmatic steps to do so.

\section{References}

Baran, S.J. \& Davis, D.K. (2009). Mass Communication Theory (5 ${ }^{\text {th }}$ ed.). Boston: Wadsworth Cengage Learning.

Benneth, W.L. \& Iyengar, S. (2008). "A New Era of Minimal effects? Changing Foundations of Political Communication." Journal of communication, 58 (4), 707 - 731.

Bonfadelli, H. (2002). "The Internet and Knowledge Gaps: A theoretical and Empirical investigation.” European Journal of communication, 17, 65 - 85.

Collins, R. (2008). "Hierarchy or Homeostasis? Hierarchy, Markets and Networks in Uk media and communications governance." Media, Culture and Society, 30 (3), 295 - 317. 
Fiddler, R. (1997). Mediamorphosis: Understanding New Media. Thousand Oaks, Calif: Pire Firge Press.

Gaziano, C. (1997). "Forecast 2000: Widening knowledge gap." Journalism and Mass Communication Quarterly, 74 (2), 237 - 264.

Grabe, M.E., Karnhaus, R. \& Yelyan, N. (2009). "Informing citizens: How people with different levels of education process TV, Newspaper and Web news." Journal of broadcasting and electronic media, 53 (1), 90 - 111.

Hargittai, E. \& Hinnant, A. (2008). "Digital Inequality.” Communication Research, 35 (5), 600 621.

Ihebuzor, N. (2012). "Social Media: Emerging Patterns of Use and Abuse". Punch, 2012 March 30. Lagos: Punch (Nig) Publishers. P.16.

Katz, J.E. \& Rice, R.E. (2002). Social Consequences of Internet Use: Access, Involvement and Interaction. Cambridge, M.A: MIT Press.

Keniston, K. \& Kumar, D. (2003). The Four Digital Divides. Delhi: Sage Publishers.

Livingstone, S. (1999). "New Media, New audiences," New media and Society, I (1), 59 - 66.

McQuail, D. (2005). Mass Communication Theory (5 ${ }^{\text {th }}$ ed.). London: Sage Publications Ltd.

McQuail, D. (2010). Mass Communication Theory (6 ${ }^{\text {th }}$ ed.). London: Sage Publications Ltd.

Ndolo, I.S. (2006). Mass Media Systems and Society. Enugu: Rhyce Kerex Publishers.

Norris, P. (2002). Digital Divide. New York : Cambridge University Press.

Obijiofor, L. (2012). "New Media: Expanding platforms of public Debate." The Guardian, April 13, 2012. Lagos: Guardian Newspapers Limited. P.51.

Odofin, B. (2011). "Revolutions, new media, other dangerous things." The Guardian, December 6. Lagos: Guardian Newspapers Limited. P.80.

Owens - Ibie, N. (2013). "Communicating An Implosion: signs and Wander, popular culture and the crumbling of Empire." Paper delivered at Caleb University, Lagos on Tuesday April 9, 2013.

Parker, E.B \& Dunn, D.A. (1972). "Information Technology: Its social potential." Science, 176, 1392 - 1398. Raji - Oyelade, A. (2013). "Fluent in (ter) ventions: Webs of the Literary Discipline." An inaugural lecture delivered at Trenchard Hall, University of Ibadan, on $14^{\text {th }}$ February 2013.

Robinson, J.P. (1972). "Mass communication and Information Diffusion." In Kline, F.G \& Tichenor, P.J. (eds.), Current Perspectives in Mass Communication Research (pp 71 93). Beverly Hills, CA: Sage. 
Robinson, J.P. \& Levy, M. (1986). The Main Source. Beverly Hills, C.A: Sage.

Rosier, P. (2001). "Between online Heaven and Cyberhell: The Framing of the Internet by Traditional media coverage in Germany." New media and Society 3 (1), 49 - 66.

Salu, G. (2012). "How to Harness Potentials of New Media." The Guardian, June 25, 2012. Lagos: Guardian Newspapers Limited. P. 71.

Selwyn, N. (2004). "Reconsidering Political and popular understanding of the Digital divide." New media and society, 6 (3), $341-362$.

Severin, W.J. \& Tankard, J.W. (1992). Communication Theories: Origins, Method and Uses in the Mass Media $\left(3^{\text {rd }}\right.$ ed.). New York: Longman.

Smith, R. \& Curtin, P. (1997). "Children, Computers and life online: Education and the cyberworld." In snyder, I. (Ed.), Page to school: Taking Literacy into the electronic era (pp. 211 - 233). St. Leonard's, NSW: Allen \& Unwin.

Tichenor, P., Donohue, G. \& Olien, C. (1970). "Mass Media Flow and Differential Growth in Knowledge.” Public Opinion Quarterly, 34, 159 - 170.

Udeze, S.E. (2005). After The Whirlwind: A Discourse on International Communication. Enugu: Rhyce Kerex Publishers.

Visvanath, K. \& Finnegan, J.R. (1996). "The knowledge gap hypothesis 25 years later." Communication year book 19, pp $187-227$.

Watson, J. (2003). Media Communication: An Introduction to Theory and Process $\left(2^{\text {nd }}\right.$ ed.). New York: Palgrave Macmillan.

Organization for Economic Cooperation and Development (2001): Understanding The Digital Divide. Paris Cede 16, France. 